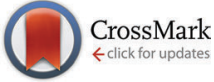

Cite this: Phys. Chem. Chem. Phys., 2015, 17, 15903

Received 28th April 2015, Accepted 13th May 2015 DOI: $10.1039 / c 5 c p 02482 j$

www.rsc.org/pccp

\title{
Correlation of electrochromic properties and oxidation states in nanocrystalline tungsten trioxide $\dagger$
}

\author{
S. Darmawi, ${ }^{a}$ S. Burkhardt, ${ }^{a}$ T. Leichtweiss, ${ }^{\text {b D. A. Weber, }}{ }^{\text {b S. Wenzel, }},{ }^{\text {b }}$ J. Janek, ${ }^{b}$ \\ M. T. Elm*ab and P. J. Klar*a
}

\begin{abstract}
Although tungsten trioxide $\left(\mathrm{WO}_{3}\right)$ has been extensively studied since its electrochromic properties were first discovered, the mechanism responsible for the coloration or bleaching effect is still disputed. New insights into the coloration mechanism of electrochromic, nanocrystalline $\mathrm{WO}_{3}$ are provided in this paper by studying thin $\mathrm{WO}_{3}$ films combining the electrochemical and spectroscopic techniques. By employing in situ UV-Vis transmission spectroscopy at a fixed spectral band pass during electrochemical experiments, such as cyclic voltammetry, a two-step insertion process for both protons and lithium ions is identified, of which one step exhibits a significantly higher coloration efficiency than the other. To obtain a better understanding of the insertion process $A_{x} W_{3}(A=H, L i, \ldots)$ thin films were studied at different stages of intercalation using UV-Vis and X-ray photoelectron spectroscopy. The results show that the first step of the intercalation process represents the reduction from initial $\mathrm{W}^{6+}$ to $\mathrm{W}^{5+}$ and the second step the reduction of $\mathrm{W}^{5+}$ to $\mathrm{W}^{4+}$. We found that the blue coloration of this nanocrystalline tungsten trioxide is mainly due to the presence of $\mathrm{W}^{4+}$ rather than that of $\mathrm{W}^{5+}$
\end{abstract}

\section{Introduction}

Electrochromism - the property of a thin film to reversibly change its transmission properties by electrochemical reduction or oxidation $^{1-4}$ - has been intensively investigated during the last few decades. ${ }^{2,4,5}$ Studies on electrochromism were first published by $\mathrm{Deb}^{6}$ in 1969 and reports on energy efficient fenestration for buildings $s^{7,8}$ followed in 1984 . Tungsten trioxide in particular is studied in more detail than any other chromogenic material for several reasons: it exhibits thermochromic, photochromic, gasochromic as well as electrochromic characteristics and is thus the most relevant material for chromogenic devices such as smart windows or gas sensors, etc. ${ }^{9-11}$ As other chromogenic oxides, such as $\mathrm{MoO}_{3}$, are somewhat similar in their properties, tungsten trioxide represents a widely used model system ${ }^{2}$ for examining the coloration processes.

The general expression for the electrochromic reaction in tungsten trioxide is given by

$$
x \mathrm{~A}^{+}+x \mathrm{e}^{-}+\mathrm{WO}_{3} \leftrightarrow \mathrm{A}_{x} \mathrm{WO}_{3},
$$

\footnotetext{
${ }^{a}$ Justus-Liebig-Universität Gießen, I. Physikalisches Institut, Heinrich-Buff-Ring 16, 35392 Gießen, Germany. E-mail: Matthias.Elm@phys.Chemie.uni-giessen.de, Peter.J.Klar@exp1.physik.uni-giessen.de; Tel: +49 641-9934544, +49 641-9933190 ${ }^{b}$ Justus-Liebig-Universität Gießen, Physikalisch-Chemisches Institut, Heinrich-BuffRing 58, 35392 Gießen, Germany

$\dagger$ Electronic supplementary information (ESI) available. See DOI: 10.1039/ с5ср02482j
}

where A is usually either an alkali metal, such as lithium or sodium, or hydrogen. ${ }^{12}$

Today two main mechanisms are usually discussed for explaining the color change in $\mathrm{A}_{x} \mathrm{WO}_{3}$ : for crystalline systems, the effects are often discussed in terms of optical transitions or collective excitation of quasi-free electrons in not fully occupied bands in a one-electron band structure (rigid-band model), whereas in the case of amorphous films the effects are often described in terms of intervalence charge transfer (IVCT). The charge transfer involves $\mathrm{W}$ atoms in different oxidation states either alone or in conjunction with additional defects such as oxygen vacancies. ${ }^{13-18}$ The coloration and bleaching processes are difficult to describe in a single-particle model, i.e. for an appropriate theoretical description coupling of the carriers to the lattice as well as electron-electron interactions need to be accounted for at least to some degree. Therefore, details of the mechanisms are still controversially discussed and a unified model for the description of crystalline as well as amorphous films is not established yet. In the following, we summarize some of the current views.

Schirmer et al. presented a model for small polaron transitions between sites A and B, both occupied by tungsten, but of different oxidation states, i.e.:

$$
h \nu+\mathrm{W}^{5+}(\mathrm{A})+\mathrm{W}^{6+}(\mathrm{B}) \rightarrow \mathrm{W}^{6+}(\mathrm{A})+\mathrm{W}^{5+}(\mathrm{B}) .
$$

The electrons that are injected during the insertion process are localized at $\mathrm{W}^{5+}$ sites, polarize their surroundings and form small polarons. ${ }^{14}$ When light is absorbed, these small polarons 
hop from one site to another. This is probably the correct picture, once we concentrate on $\mathrm{W}^{6+} \leftrightarrows \mathrm{W}^{5+}$ charge transfer in the early state of reduction.

In bandstructure theory of crystalline materials, polarons go beyond the one-electron picture. They are technically dealt with as conduction band electrons accompanied by a spontaneous lattice deformation. This may be crudely incorporated into the oneelectron picture as levels splitting off the bottom of the singleparticle conduction band as a result of considering electron-phonon coupling as a perturbation. Electrons injected from the cathode due to insertion of alkali or hydrogen fill these states in the conduction band. Optical absorption is thus generated by optical transitions between occupied and unoccupied states. ${ }^{10,17}$

However, the details of the mechanisms are strongly debated: Zhang et al. also reported on small polaron absorption for amorphous $\mathrm{WO}_{3}$, but in this case with transitions between $\mathrm{W}^{5+}$ and $\mathrm{W}^{4+}$ sites. ${ }^{15}$ Broclawik et al. introduced a $\mathrm{WO}_{6}$ octahedra cluster model that bridges the gap between models for crystalline and amorphous $\mathrm{WO}_{3}{ }^{17}$ Deb et al. proposed a new model, based on the presence of oxygen vacancies (analogous to F-centers) with associated $\mathrm{W}^{4+}$ ions. ${ }^{16}$ In a recent study, Limaye et al. performed in situ XANES on crystalline $\mathrm{WO}_{3}$ and found that coloration/bleaching is due to filling/unfilling of the $\mathrm{W}$ $5 \mathrm{~d}-\mathrm{O} 2 \mathrm{p}$ hybridized conduction band states. They also object to the intervalence transition between different tungsten sites and the formation of polarons. Based on their results, they could not verify a corresponding change in the nearest-neighbor $\mathrm{W}-\mathrm{O}$ bond distances. ${ }^{19}$ Zhong et al. generally object to utilizing the rigid band model for charge transfer of the inserted electrons, i.e. a quick change in the crystal phase upon ion insertion destroys the validity of the rigid band model. ${ }^{20}$

Thus, to date it is not clear whether all mechanisms leading to the coloration in the various $\mathrm{WO}_{3}$ phases are known and to which extent they differ for different phases. With our study we add some additional experimental evidence which suggests that the presence of $\mathrm{W}^{4+}$ is essential for the coloration of nanocrystalline $\mathrm{WO}_{3}$. We analyze the electrochromic properties of nanocrystalline tungsten trioxide thin films prepared via a dip coating process. Dip coating is a versatile and cost-effective fabrication technique which due to its scalability is also of interest for industrial applications where a film deposition on large areas is required. By employing in operando optical transmission spectroscopy during both cyclic voltammetric and galvanostatic experiments we were able to identify a two-step insertion process for both protons and lithium ions, of which only one step causes significant coloration. To obtain further insight into the nature of this two-step mechanism, the oxidation state of tungsten as well as the crystallinity of the $\mathrm{WO}_{3}$ thin films prepared was analyzed as a function of the amount of the inserted charge.

\section{Experimental details}

\subsection{Sample preparation}

The preparation process for nanocrystalline $\mathrm{WO}_{3}$ thin films was adopted from Brezesinski et al. ${ }^{21}$ A solution consisting of $1.19 \mathrm{~g}$ of $\mathrm{WCl}_{6}$ in $4.8 \mathrm{~g}$ of ethanol was stirred for approximately $12 \mathrm{~h}$. Approximately $10 \mathrm{mg}$ of a block-copolymer (Pluronic 127) was used for reduction of the surface tension. Thin films were prepared by dip coating on FTO substrates (sheet resistance of $7 \Omega \mathrm{sq}^{-1}$ ) in a controlled air atmosphere (relative humidity $<$ $10 \%$ ) at a constant withdrawal rate of $10 \mathrm{~mm} \mathrm{~s}^{-1}$. After deposition, the films were dried for $1 \mathrm{~h}$ at $100{ }^{\circ} \mathrm{C}$ and $12 \mathrm{~h}$ at $300{ }^{\circ} \mathrm{C}\left(\operatorname{ramp} 2{ }^{\circ} \mathrm{C} \min ^{-1}\right)$.

Annealing the samples in air at $450{ }^{\circ} \mathrm{C}$ for 30 minutes with a ramp rate of $5{ }^{\circ} \mathrm{C} \mathrm{h}^{-1}$ resulted in nanocrystalline $\mathrm{WO}_{3}$. The resulting layers have a thickness of about $100 \mathrm{~nm}$.

\subsection{Electrochemical experiments}

Proton insertion, using $0.1 \mathrm{M} \mathrm{H}_{2} \mathrm{SO}_{4}$ in $\mathrm{H}_{2} \mathrm{O}$ as an electrolyte, was carried out in a specially designed compact three-electrode cell (adapted from Wallys et al. ${ }^{22}$ ) consisting of a $3 \mathrm{M} \mathrm{KCl}$ $\mathrm{Ag} / \mathrm{AgCl}$ reference electrode $\left(E_{0}=0.21 \mathrm{~V} v s\right.$. SHE, Driref-450 microreference, WPI) and a platinum counter electrode. The geometrical area of the $\mathrm{WO}_{3}$ working electrode was $0.07 \mathrm{~mm}^{2}$. Electrochemical tests were performed using a Jaissle IMP 83 PC potentiostat.

Lithium insertion, using $0.2 \mathrm{M} \mathrm{LiClO}_{4}$ in propylene carbonate (PC) as an electrolyte, was carried out in a different, also specially designed compact three-electrode cell, consisting of a lithium reference electrode and a lithium counter electrode. The cell was assembled inside a glove box in an argon atmosphere with controlled $\mathrm{H}_{2} \mathrm{O}$ and $\mathrm{O}_{2}$ concentrations of less than 5 ppm and 0.1 ppm respectively. A Bio-logic sp300 potentiostat was used. The geometrical area of the $\mathrm{WO}_{3}$ working electrode was $0.07 \mathrm{~mm}^{2}$.

For transmission experiments, the films were illuminated by a halogen lamp. In the case of lithium insertion, the transmission was detected spectrally resolved using a spectrometer (LR1 spectrometer, ASEQ) whereas, in the case of hydrogen insertion, a subtractive double spectrometer (Spex 1680 b, Horiba) equipped with a CCD-Camera (pco1400) was used to detect light in a spectral window of $633 \mathrm{~nm} \pm 15 \mathrm{~nm}$.

Cyclic voltammetry experiments were carried out starting at the open circuit potential with a scan rate of $1 \mathrm{mV} \mathrm{s}^{-1}$ towards lower potentials. In the case of hydrogen insertion the investigated voltage range was between $1 \mathrm{~V}$ and $-0.6 \mathrm{~V}$ vs. $\mathrm{Ag} / \mathrm{AgCl}$, while in the case of lithium insertion the voltage range was varied from $4 \mathrm{~V}$ to $1.7 \mathrm{~V} v s$. $\mathrm{Li} / \mathrm{Li}^{+}$.

\subsection{Spectroscopic characterization}

UV-Vis transmission spectroscopy was performed on a Perkin Elmer Lambda 900 spectrometer. The integration time was $0.16 \mathrm{~s}$ and the scan speed was $300 \mathrm{~nm} \mathrm{~s}^{-1}$ for the UV-Vis range and $375 \mathrm{~nm} \mathrm{~s}^{-1}$ for the NIR range with a spectral resolution of $5 \mathrm{~nm}$.

Samples for ex situ XPS and UV-Vis analyses were prepared as follows: the galvanostatic lithium insertion was carried out inside a glove box. A two-electrode setup inside a cuvette with lithium foil as a counter electrode was employed. Stainless steel screws were used as electric contacts and for fixing the counter electrode and the sample. 
XPS measurements were performed using a PHI 5000 Versaprobe Scanning ESCA Microprobe (Physical Electronics, Inc.) equipped with a monochromatic aluminum X-ray source (beam area $200 \mu \mathrm{m} \times 1400 \mu \mathrm{m}$, X-ray power $100 \mathrm{~W}$ ) at a chamber pressure of around $10^{-8} \mathrm{mbar}$. Pass energy for high resolution spectra was $23.5 \mathrm{eV}$ with an energy step width of $0.1 \mathrm{eV}$. The spectra were analyzed using the CasaXPS software package (Version 2.3.17dev6.3y). The spectra were energy calibrated by shifting the binding energy of the adventitious carbon signal to a position of $284.8 \mathrm{eV}$.

\subsection{Structural investigations}

Structural investigations on pristine and lithium-inserted samples were carried out by X-ray diffraction (XRD), using a PANalytical Empyrean diffractometer with $\mathrm{Cu} \mathrm{K} \alpha$ radiation $\left(\lambda_{1}=154.056 \mathrm{pm}\right.$, $\lambda_{2}=154.539 \mathrm{pm}, I\left(\lambda_{1} / \lambda_{2}=0.5\right)$ in Bragg-Brentano $\theta-\theta$ geometry. Diffraction diagrams were recorded in a $2 \theta$ range from $10^{\circ}$ to $90^{\circ}$ with a step size of $0.013^{\circ}$ and a counting time of $270 \mathrm{~s}$ per step. Additional powder samples (see Results section) were measured in a similar manner, but with a step size of $0.026^{\circ}$.

\section{Results}

\subsection{Cyclic voltammetry and transmission}

For the discussion of the electrochromic properties of nanocrystalline $\mathrm{WO}_{3}$ films we use various representations of the spectro-electrochemical data, which are introduced in the following. In a typical cyclic voltammogram (CV) the amount of transferred charge per unit time (i.e. electric current) is analyzed as a function of the working electrode potential $\left(\mathrm{WO}_{3}\right.$ thin film). It is worth mentioning that the cell current, due to the constant rate of change of potential $E$, i.e. a constant scan rate $v=\mathrm{d} E / \mathrm{d} t\left[\mathrm{~V} \mathrm{~s}^{-1}\right]$, is directly proportional to the differential capacity $(\mathrm{d} Q / \mathrm{d} E)$ during a CV experiment:

$$
I=\mathrm{d} Q / \mathrm{d} t=v \cdot \mathrm{d} Q / \mathrm{d} E .
$$

The change in transmission as a function of electrode potential can be analyzed in order to further correlate the amount of transferred electric charge with the change in film coloration:

$$
\mathrm{d} T / \mathrm{d} E=v^{-1} \cdot \mathrm{d} T / \mathrm{d} t
$$

Finally, we can derive the coloration efficiency using,

$$
\eta=\mathrm{d}(\mathrm{OD}) / \mathrm{d} Q \text {. }
$$

Here OD is the optical density given by $\ln \left(T_{0} / T\right)$, where $T_{0}$ and $T$ are the transmittance of the thin film in its initial and colored state, respectively.

As an example, Fig. 1(a) shows the first cycle of a cyclic voltammogram of a $\mathrm{WO}_{3}$ thin film in aqueous $\mathrm{H}_{2} \mathrm{SO}_{4}$. The cell current is plotted versus the applied working electrode potential $E$ measured with respect to the $\mathrm{Ag} / \mathrm{AgCl}$ reference electrode. Starting at the open circuit potential, around $0.29 \mathrm{~V} v s . \mathrm{Ag} / \mathrm{AgCl}$, the potential is reduced at a rate of $v=1 \mathrm{mV} \mathrm{s}^{-1}$. The resulting negative current causes insertion of electrons and ions, in this case protons, into the tungsten trioxide film. This process

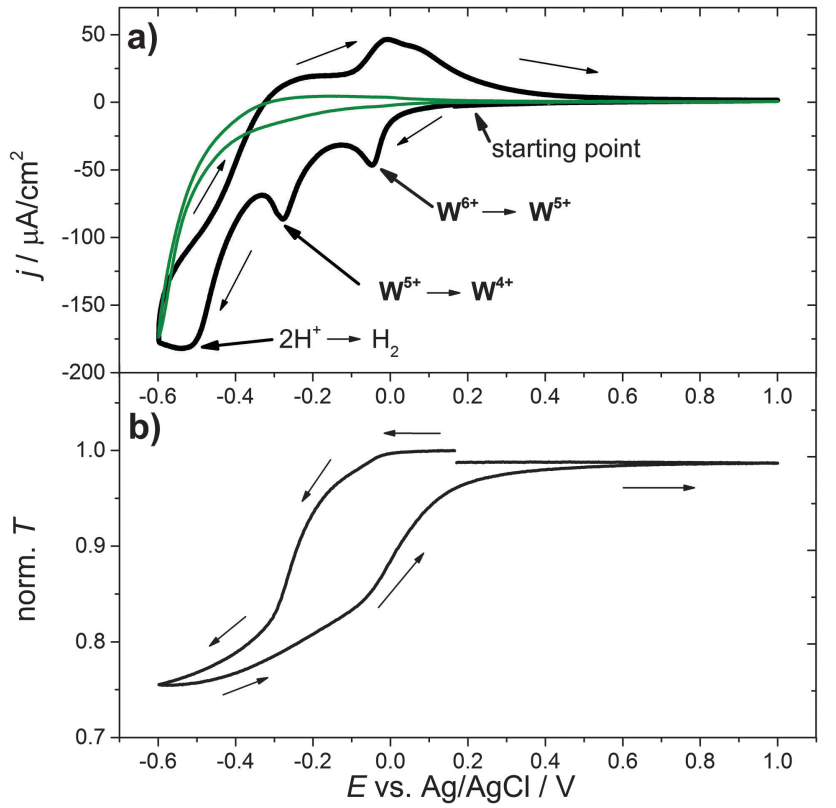

Fig. 1 (a) Cyclic voltammogram of a $\mathrm{WO}_{3}$ film in a $0.1 \mathrm{M} \mathrm{H}_{2} \mathrm{SO}_{4}$ in $\mathrm{H}_{2} \mathrm{O}$ electrolyte with a scan rate of $1 \mathrm{mV} \mathrm{s}^{-1}$. The green curve shows the same measurement for the substrate alone. (b) Corresponding transmission characteristics during hydrogen insertion recorded for a spectral window of $633 \mathrm{~nm} \pm 15 \mathrm{~nm}$. Norm. T denotes the transmission $T$ at the center wavelength $633 \mathrm{~nm}$ normalized to the corresponding transmission $T_{0}$ at the beginning of the experiment.

results in a bluish coloration of $\mathrm{WO}_{3}$. At around $-0.05 \mathrm{~V} v s$. $\mathrm{Ag} / \mathrm{AgCl}$ and $-0.3 \mathrm{~V} v$ s. $\mathrm{Ag} / \mathrm{AgCl}$ maxima of the negative current, "reduction peaks", are observed. The strong current increase at $-0.6 \mathrm{~V}$ vs. $\mathrm{Ag} / \mathrm{AgCl}$ can be attributed to the unwanted side reactions at the substrate, such as hydrogen evolution or substrate decomposition. For comparison, a CV measurement which was performed for the substrate only is shown as a green curve. Fig. 1(b) shows the corresponding transmission characteristics of the same $\mathrm{WO}_{3}$ sample. The transmission decreases as the cathodic current increases to more negative values, meaning that with an increase in the amount of inserted hydrogen the coloration of the material increases. The coloration process is reversible, i.e. with decreasing cathodic current the transmission increases again. At $-0.6 \mathrm{~V} v s$. $\mathrm{Ag} / \mathrm{AgCl}$ the scan direction is reversed and the potential is increased at a rate of $1 \mathrm{mV} \mathrm{s}^{-1}$. At approximately $-0.4 \mathrm{~V}$ vs. $\mathrm{Ag} / \mathrm{AgCl}$, positive cell currents are observed that correspond to a net oxidation (hydrogen extraction) of the $\mathrm{WO}_{3}$ film.

To further examine the electrochemical coloration process, the change in transmission with time $(\mathrm{d} T / \mathrm{d} t)$ is analyzed. As a constant scan rate $\left(v=1 \mathrm{mV} \mathrm{s}^{-1}\right)$ was used, this is equivalent to the change in transmission with potential $(\mathrm{d} T / \mathrm{d} E)$. Fig. 2(a) shows the transmission change $\mathrm{d} T / \mathrm{d} t$ vs. $E$ and the corresponding cyclic voltammogram. It can be seen that the change in transmission, $\mathrm{d} T / \mathrm{d} t$, peaks at the same potential values as the current density $j$. The first current peak at $E=-0.05 \mathrm{~V}$ is significantly smaller than the second one at $E=-0.3 \mathrm{~V}$ (assuming a peak baseline of zero current). The corresponding transmission 


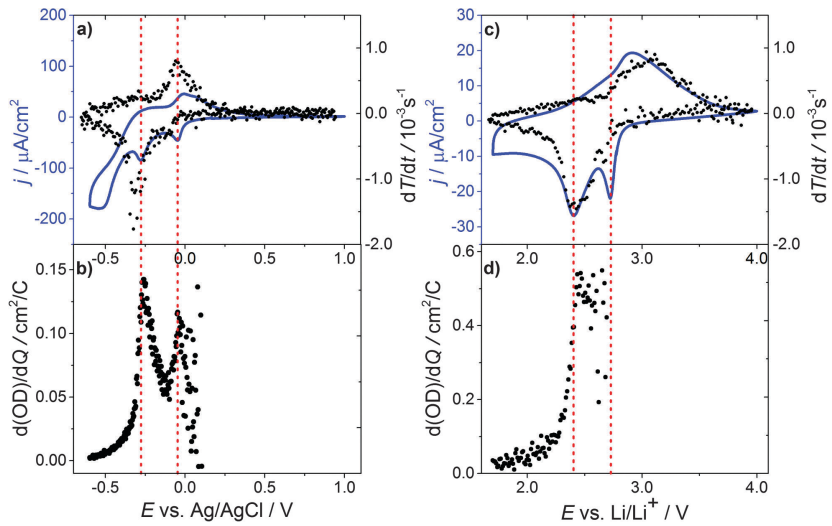

Fig. 2 Transmission change dT/dt vs. $E$ and the cyclic voltammogram of a $W_{3}$ film in: (a) $0.1 \mathrm{M} \mathrm{H}_{2} \mathrm{SO}_{4}$ in $\mathrm{H}_{2} \mathrm{O}$ and (c) $0.2 \mathrm{M} \mathrm{LiClO}_{4}$ in propylene carbonate. Change in the optical density with respect of the amount of (b) inserted protons/electric charge $\mathrm{d}(\mathrm{OD}) / \mathrm{d} Q$ vs. $E$ and (d) inserted lithium ions/electric charge $\mathrm{d}(\mathrm{OD}) / \mathrm{d} Q$ vs. $E$.

peaks show a similar behavior. The second current peak is more distinct and $\mathrm{d} T / \mathrm{d} t$ is also significantly larger. At a first glance, a high cell current results in a high transmission change in the $\mathrm{WO}_{3}$ layer. To obtain more quantitative information we analyzed the differential transmission with respect to the coloration efficiency as a function of the electrode potential. The change in optical density with respect to the amount of inserted protons, i.e. electric charge, $\mathrm{d}(\mathrm{OD}) / \mathrm{d} Q v s$. $E$, for the first coloration half-cycle is plotted in Fig. 2(b). It can be seen that for the first current peak at $-0.05 \mathrm{~V}$ vs. $\mathrm{Ag} / \mathrm{AgCl}$ the coloration efficiency $\mathrm{d}(\mathrm{OD}) / \mathrm{d} Q$ is smaller than for the current peak at $-0.3 \mathrm{~V}$, which is more distinct and has a value of about $0.15 \mathrm{~cm}^{2} \mathrm{C}^{-1}$. The mechanism of hydrogen insertion and $\mathrm{WO}_{3}$ reduction seems to be a two-step process that takes place over a range of electrode potentials.

Fig. 3(a) displays the differential change in the optical density $\mathrm{d}(\mathrm{OD}) / \mathrm{d} E$ and $\mathrm{d} Q / \mathrm{d} E$ vs. $E$, which in this case basically represents the cell current. Merely a shoulder in $\mathrm{d}(\mathrm{OD}) / \mathrm{d} E$ is visible at the first current peak $(E=-0.05 \mathrm{~V} v s$. $\mathrm{Ag} / \mathrm{AgCl})$, while
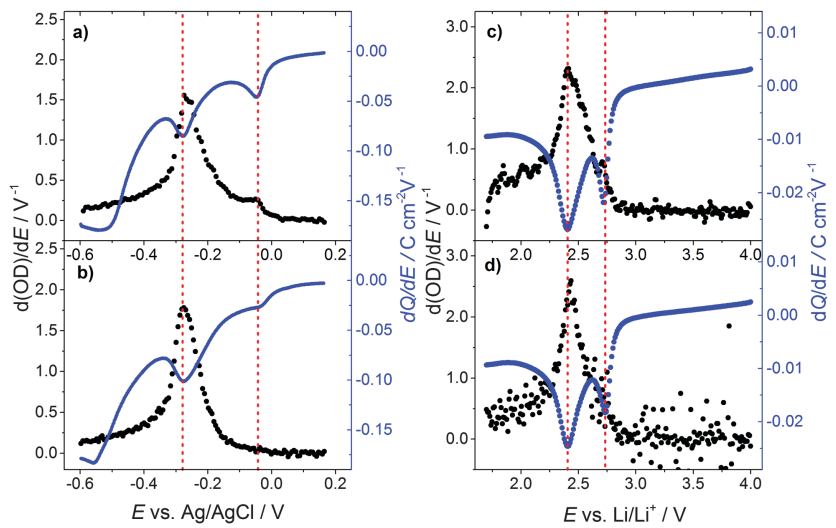

Fig. 3 Differential change of the optical density $\mathrm{d}(\mathrm{OD}) / \mathrm{d} E$ vs. $E$ and $\mathrm{d} Q / \mathrm{d} E$ (cell current) vs. $E$ of a $\mathrm{WO}_{3}$ film for the potential decreasing part of a cyclic voltammogram with a scan rate of $1 \mathrm{mV} \mathrm{s}^{-1}$ (a) in $0.1 \mathrm{M} \mathrm{H}_{2} \mathrm{SO}_{4}$ in $\mathrm{H}_{2} \mathrm{O}$ for the first cycle and (b) the 10th cycle; (c) in $0.2 \mathrm{M} \mathrm{LiClO}_{4}$ in PC for the first cycle and (d) the 10th cycle. at the second current peak $(E=-0.3 \mathrm{~V}$ vs. $\mathrm{Ag} / \mathrm{AgCl})$ the main transmission change is observed.

Fig. 3(b) shows $\mathrm{d}(\mathrm{OD}) / \mathrm{d} E$ and $\mathrm{d} Q / \mathrm{d} E$ vs. $E$ after the 10 th $\mathrm{CV}$ cycle of the sample. The first current peak is reduced significantly and the $\mathrm{d}(\mathrm{OD}) / \mathrm{d} E$ feature of this potential vanishes. The $\mathrm{d}(\mathrm{OD}) / \mathrm{d} E$ peak at $-0.3 \mathrm{~V}$ vs. $\mathrm{Ag} / \mathrm{AgCl}$ becomes narrower and higher. Analyzing the electrochromic properties of $\mathrm{WO}_{3}$ films using aqueous acid based electrolytes, however, is problematic for the following reasons. As can be seen from Fig. 1(a) substrate reduction and/or hydrogen evolution cause a high parasitic current and eventually lead to ageing of the films. Moreover, other side reactions, such as self-bleaching, ${ }^{23,24}$ lead to currentfree discoloration of the films.

Thus, in order to overcome these problems, a similar series of measurements was carried out using lithium ions in a water and oxygen free environment instead of hydrogen. Fig. 2(c) shows the corresponding cyclic voltammogram and $\mathrm{d} T / \mathrm{d} t v s . E$. In the $\mathrm{CV}$ curve, two reduction peaks at $2.73 \mathrm{~V} v s . \mathrm{Li} / \mathrm{Li}^{+}$and $2.4 \mathrm{~V} v s . \mathrm{Li} / \mathrm{Li}^{+}$are observed. As for proton insertion, the peaks are about $0.3 \mathrm{~V}$ apart. Peak currents, however, are a factor of 10 smaller compared to the measurements in aqueous solutions, while the transmission change is about the same, showing that $\mathrm{WO}_{3}$ coloration via $\mathrm{Li}$ insertion is more effective. In addition, the reduction peaks for lithium insertion are narrower and more pronounced than the corresponding peaks for hydrogen, which can be interpreted in terms of a more well-defined phase transition for $\mathrm{Li}$ ions than for protons. After the major transmission change at $2.4 \mathrm{~V} v s$. $\mathrm{Li} / \mathrm{Li}^{+}$the current almost relaxes towards zero.

The coloration efficiency $\mathrm{d}(\mathrm{OD}) / \mathrm{d} Q$ (Fig. 2(d)) for the first peak at $2.73 \mathrm{~V} v s$. $\mathrm{Li} / \mathrm{Li}^{+}$is very small and hardly discernable as differentiating with respect to $Q$ leads to strong scattering of the values for $Q$ close to zero. A distinct peak occurs for the second current peak at $2.4 \mathrm{~V} v s$. $\mathrm{Li} / \mathrm{Li}^{+}$with a value of about $0.6 \mathrm{~cm}^{2} \mathrm{C}^{-1}$, which is a factor of 4 higher than for hydrogen insertion.

Fig. 3(c) shows $\mathrm{d}(\mathrm{OD}) / \mathrm{d} E$ vs. $E$ and $\mathrm{d} Q / \mathrm{d} E v s$. $E$ for the first cycle of lithium injection. As to the case of proton insertion, the main transmission change occurs in the vicinity of the second current peak. Again, the first current peak results in a comparably small differential transmission change only. After the tenth cycle (Fig. 3(d)), peak currents are reduced by approximately $20 \%$ for the first peak and 10\% for the second one. The first peak in transmission change is also reduced but still clearly visible.

The results in Fig. 1-3 clearly indicate a two-step insertion process for both hydrogen and lithium insertion into nanocrystalline $\mathrm{WO}_{3}$ thin films, of which the first reduction step at a higher electrode potential is characterized by both a lower amount of the inserted electric charge and, more importantly, by a significantly lower coloration efficiency compared to the second step.

Cycling the films several times leads to an extinction of the bump in differential transmission change due to the first reduction peak in the case of hydrogen insertion, and to a noticeable decrease in the case of lithium insertion.

\subsection{UV-Vis transmission spectroscopy}

To obtain a better understanding of the insertion process, we analyzed the inserted $\mathrm{WO}_{3}$ thin films at different stages of 
lithiation, using UV-Vis, X-ray photoelectron spectroscopy (XPS) and X-ray diffraction (XRD) analysis. As already mentioned above, hydrogen insertion into $\mathrm{WO}_{3}$ is accompanied by selfbleaching and parasitic electrochemical processes of the FTO substrate and we therefore focus on $\mathrm{Li}$ inserted $\mathrm{WO}_{3}\left(\mathrm{Li}_{x} \mathrm{WO}_{3}\right)$ samples in the following. Furthermore, instead of CV experiments, Li insertion was carried out by galvanostatic discharge. In galvanostatic experiments, ion insertion into the $\mathrm{WO}_{3}$ thin film is not as dynamic as in CV experiments with a preset rate. The potential saturates when a certain state is attained and during that time more charge, i.e. more ions are inserted at the same potential value.

To make sure that the first insertion step is not accompanied by a significant transmission change in a different spectral window than the $633 \mathrm{~nm}$ monitored previously, UV-Vis transmission spectroscopy was employed in the entire range from $300 \mathrm{~nm}$ to $1300 \mathrm{~nm}$. For this measurement the films were discharged by a constant current of -300 nA. Fig. 4(a) shows the curve for the galvanostatic discharge of $\mathrm{WO}_{3}$. Starting at the open circuit potential, at around $E=2.9 \mathrm{~V}$, within the range of $Q=0 \mathrm{mC} \mathrm{cm}^{-2}$ to $2 \mathrm{mC} \mathrm{cm}{ }^{-2}$ the curve displays an s-shaped form with a rapid potential drop. The cell potential of $E=2.76 \mathrm{~V}$ at around $1 \mathrm{mC} \mathrm{cm}^{-2}$ is described by a plateau-like potential curve. Then another s-shaped form of the potential develops the potential decreases over a wider range with a more shallow slope until a second s-shaped form appears at $Q=2.5 \mathrm{mC} \mathrm{cm}^{-2}$ with a value of $E=2.55 \mathrm{~V}$. The second plateau-like step spreads within a wider range than the first, i.e. from about $3 \mathrm{mC} \mathrm{cm}^{-2}$ to $7 \mathrm{mC} \mathrm{cm}^{-2}$. At $7 \mathrm{mC} \mathrm{cm}^{-2}$ the potential decreases again but with an even smaller slope. These two plateau-like potential curves correspond to the current peaks of the cyclic voltammograms.

For the ex situ UV-Vis transmission experiment, the discharge was stopped at $2.73 \mathrm{~V}$ (and held at that potential for $30 \mathrm{~min}$ ) and $2.45 \mathrm{~V}$, which are the ends of each insertion step indicated by the plateau-like potential curves at $2.76 \mathrm{~V}$ and $2.55 \mathrm{~V}$, respectively, as displayed in Fig. 4(a). In the following, the potential values $E=$ $2.73 \mathrm{~V}$ and $2.45 \mathrm{~V}$, where the discharge was stopped, will be
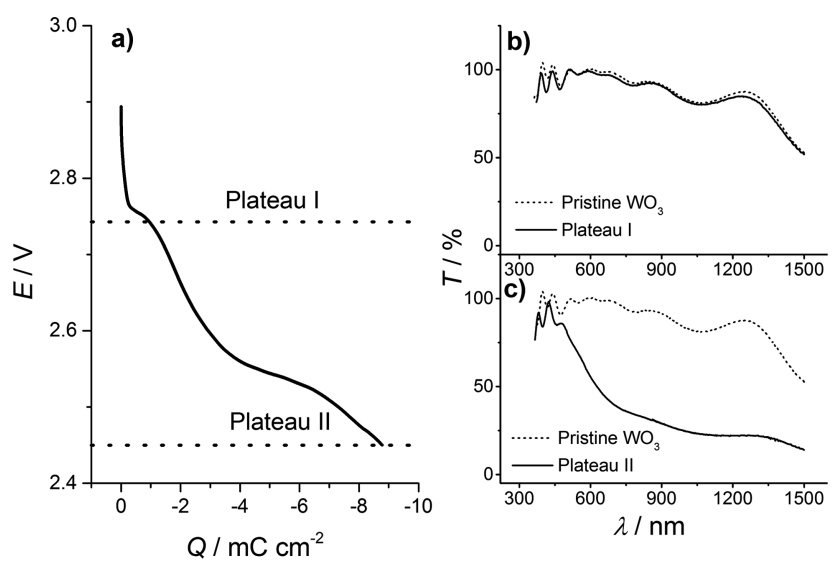

Fig. 4 (a) Correlation of charge and potential for a galvanostatic insertion process of lithium ions into a $\mathrm{WO}_{3}$ thin film in $0.2 \mathrm{M} \mathrm{LiClO}_{4}$ in $\mathrm{PC}$ for a constant current of $-300 \mathrm{nA}$. Ex situ UV-Vis spectra of $\mathrm{WO}_{3}$ films inserted up to (b) plateau I at $2.73 \mathrm{~V}$ and (c) plateau II at $2.45 \mathrm{~V}$. denoted plateau I and plateau II, respectively. After the insertion step, the samples were washed in dimethyl carbonate and dried in the argon atmosphere of the glove box. As a reference for the UV-Vis transmission spectroscopy, a FTO substrate was used. Transmission data for the states of the $\mathrm{WO}_{3}$ film corresponding to plateaus I (at $2.73 \mathrm{~V}$ ) and II (at $2.45 \mathrm{~V}$ ) are shown in Fig. 4(b) and (c) in comparison with the corresponding data for the pristine film. The transmission curves of the pristine film and the film in a state corresponding to plateau I look almost identical. A large transmission change appears for a film in a state corresponding to plateau II, where its transmission dramatically drops for wavelengths beyond $500 \mathrm{~nm}$. The data support our findings that the first insertion step shows almost no electrochromic effect.

\subsection{XPS analysis}

Obviously a significant fraction of inserted lithium does not contribute to the coloration of the $\mathrm{WO}_{3}$ thin films. As ions are inserted together with electrons the insertion is essentially equivalent to the chemical reduction of the material and one may ask whether there is also a two-step process for the reduction of $\mathrm{WO}_{3}$. In order to answer this question with ex situ XPS measurements, films were prepared by galvanostatic insertion with a constant current of $-300 \mathrm{nA}$. After stopping the insertion at $2.73 \mathrm{~V}$ (plateau I) and $2.45 \mathrm{~V}$ (plateau II), respectively, the $\mathrm{Li}_{x} \mathrm{WO}_{3}$ samples and the pristine $\mathrm{WO}_{3}$ film were washed in dimethyl carbonate and dried in the argon atmosphere of the glove box. Afterwards, the films were transferred into the X-ray photoelectron spectrometer avoiding contact with the atmosphere. Besides a small carbon contamination from the sample preparation and/or electrochemical intercalation only tungsten and oxygen species were detected.

Fig. 5 shows the $\mathrm{W} 4 \mathrm{f}$ core level spectra of the films corresponding to three different charge states. As expected, uncolored pristine $\mathrm{WO}_{3}$ exhibits a single $\mathrm{W}$ 4f doublet with peak positions of $\mathrm{W} 4 \mathrm{f}_{7 / 2}$ at $35.4 \mathrm{eV}$ and $\mathrm{W} 4 \mathrm{f}_{5 / 2}$ at $37.6 \mathrm{eV}$ which can be clearly attributed to the $\mathrm{W}^{6+}$ oxidation state. A weak emission originating from the $\mathrm{W} 5 \mathrm{p}_{3 / 2}$ level can be found at $41.2 \mathrm{eV}$.

Developing a consistent peak model for the $\mathrm{W} 4 \mathrm{f}$ core levels of tungsten trioxide with varying degrees of reduction is a major challenge mainly due to the overlap of the $\mathrm{W} 5 \mathrm{p}_{3 / 2}$ signal with the $\mathrm{W} 4 \mathrm{f}$ lines, but also due to the unknown degree of asymmetry caused by the interaction of core holes with conduction electrons and due to the unknown shape of the inelastic background. Moreover, electrochemical insertion of lithium could lead to a non-homogeneous depth distribution of oxidation states. Nevertheless, by applying constraints on peak area ratios $\left(\mathrm{W} 4 \mathrm{f}_{7 / 2}\right.$ to $\mathrm{W}$ $4 \mathrm{f}_{5 / 2}=4: 3, \mathrm{~W} 5 \mathrm{p}_{3 / 2}$ to $\mathrm{W} 4 \mathrm{f}_{7 / 2} \approx 10: 1$ as determined for the pristine film), peak positions $\left(\Delta \mathrm{BE}\left(\mathrm{W} 4 \mathrm{f}_{5 / 2}-\mathrm{W} 4 \mathrm{f}_{7 / 2}\right)=2.1-2.2 \mathrm{eV}\right)$ and line widths $\left(F W H M\left(W 4 f_{5 / 2}\right)=\operatorname{FWHM}\left(W 4 f_{7 / 2}\right) \pm 0.05 \mathrm{eV}\right)$ for each set of components, we were able to roughly estimate the relative amounts of different oxidation states. To account for the metallic character of the ion-intercalated samples the spectra were fitted with asymmetric line shapes with additional tail damping (LF function) as implemented in the CasaXPS software. ${ }^{25}$ 


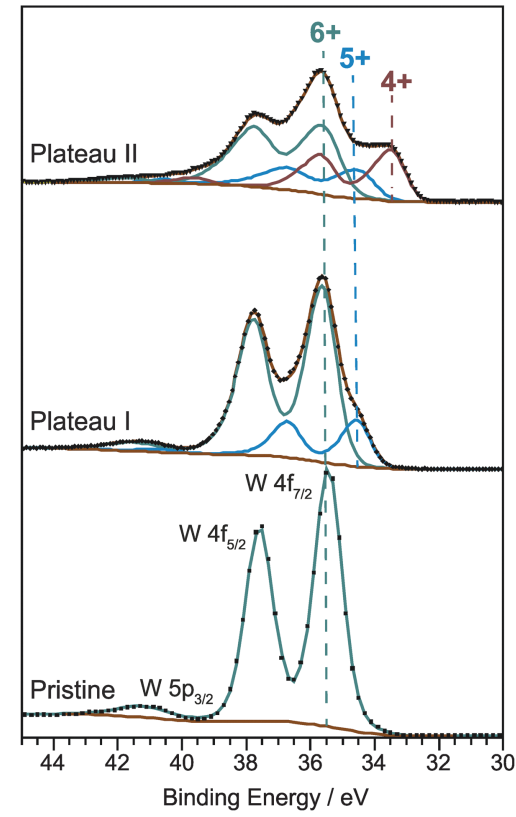

Fig. $5 \mathrm{~W} 4 \mathrm{f}$ core level XP spectra of the pristine $\mathrm{WO}_{3}$ film. Lithium inserted $\mathrm{WO}_{3}$ films formed by galvanostatic discharge in $0.2 \mathrm{M} \mathrm{LiClO}_{4}$ in $\mathrm{PC}$ with a constant current of $-300 \mathrm{nA}$ down to the first plateau at $2.73 \mathrm{~V}$ and the second plateau at $2.45 \mathrm{~V}$.

The parameters obtained from the fitting procedure are listed in Table 1.

The degree of asymmetry is given by the asymmetry index which is defined as $1-\frac{\mathrm{HWHM}_{\text {left }}}{\mathrm{HWHM}_{\text {right }}}$ where $\mathrm{HWHM}_{\text {left }}$ and $\mathrm{HWHM}_{\text {right }}$ denote the peak width at half-maximum for the respective side. It should be noted that in order to fulfill the area constraints on the high binding energy (BE) side of the $\mathrm{W}$ uf spectra the Shirley type background for the pristine and the first inserted sample corresponding to plateau I was blended with a spline function.

After the first insertion step the $\mathrm{W}$ 4f core level spectrum of the sample corresponding to plateau I displays a second doublet peak with a maximum position at $34.5 \mathrm{eV}$ for the $\mathrm{W} 4 \mathrm{f}_{7 / 2}$ line and a fractional area of $20 \%$ of the total $\mathrm{W}$ 4f signal. This doublet can be assigned to $\mathrm{W}^{5+} \cdot{ }^{26-30}$ Further ion insertion, up to the second potential plateau, then leads to an even more pronounced shoulder on the low binding energy side of the $\mathrm{W}$ 4f signal. For fitting the resulting spectrum a third doublet line at $33.3 \mathrm{eV}$ has to be added to the model. This component can be

Table 1 Parameters from peak fit analysis of the W $4 \mathrm{f}$ core levels

\begin{tabular}{|c|c|c|c|c|c|}
\hline Sample & $\begin{array}{l}\text { Formal W } \\
\text { oxidation } \\
\text { state }\end{array}$ & $\begin{array}{l}\text { Binding } \\
\text { energy } \\
\mathrm{W} 4 \mathrm{f}_{7 / 2}(\mathrm{eV})\end{array}$ & $\begin{array}{l}\text { FWHM } \\
\text { W } 4 f_{7 / 2} \\
(\mathrm{eV})\end{array}$ & $\begin{array}{l}\text { Asymmetry } \\
\text { index }\end{array}$ & $\begin{array}{l}\text { Relative } \\
\text { amount } \\
(\%)\end{array}$ \\
\hline Pristine & $6+$ & 35.4 & 1.0 & 0 & 100 \\
\hline \multirow{2}{*}{ Plateau I } & $6+$ & 35.5 & 1.1 & 0.13 & 80 \\
\hline & $5+$ & 34.5 & 1.0 & 0.13 & 20 \\
\hline \multirow[t]{3}{*}{ Plateau II } & $6+$ & 35.4 & 1.3 & 0.3 & 50 \\
\hline & $5+$ & 34.3 & 1.3 & 0.3 & 20.4 \\
\hline & $4+$ & 33.3 & 1.1 & 0.3 & 29.6 \\
\hline
\end{tabular}

attributed to $\mathrm{W}^{4+}$ species and has a relative peak area of $29.6 \%$ $\left(\mathrm{W}^{6+}: 50 \%, \mathrm{~W}^{5+}: 20.4 \%\right) .{ }^{26-28}$ Thus the XPS results prove that the lithium insertion is accompanied by a two-step reduction of tungsten. In the first step $\mathrm{W}^{6+}$ is reduced to $\mathrm{W}^{5+}$, and in the second step $\mathrm{W}^{4+}$ is formed in addition.

From our findings, we conclude that the formation of $\mathrm{W}^{4+}$ is responsible for the electrochromic behavior of nanocrystalline tungsten trioxide. Samples containing $\mathrm{W}^{5+}$ exhibit only a very small degree of coloration.

It should be remembered that XPS is a surface sensitive analysis and has an information depth for $\mathrm{W}$ 4f electrons in $\mathrm{WO}_{3}$ of about $7 \mathrm{~nm}$. However, our sol-gel based films are porous exhibiting crystallites with sizes of $20 \mathrm{~nm}$ and without a preferred orientation. Thus our XPS analysis to a large degree also gives information about the bulk of the crystallites.

The coloration in $\mathrm{WO}_{3}$ associated with the existence of $\mathrm{W}^{4+}$ has been proposed in the literature, however, there are significant differences to our findings.

In the work of Deb et al. ${ }^{16}$ the presence of $\mathrm{W}^{4+}$ was correlated to the presence of an oxygen vacancy meaning that equal concentrations of oxygen vacancies and $\mathrm{W}^{4+}$ are present. For our findings, i.e. $30 \% \mathrm{~W}^{4+}$ after intercalation, this would require $10 \%$ of oxygen sites being vacant $\left(\mathrm{WO}_{2.7}\right)$. Such a large amount of oxygen vacancies in crystalline $\mathrm{WO}_{3}$ is very unlikely. In addition, our XPS analysis clearly shows that the pristine films are almost stoichiometric, as solely $\mathrm{W}^{6+}$ is found. From this we can conclude that the formation of $\mathrm{W}^{4+}$ does not require oxygen vacancies in crystalline $\mathrm{WO}_{3}$, but results from electrochemical reduction via lithium insertion (formation of lithium interstitials, $\mathrm{Li}_{\mathrm{i}}$ ):

$$
\mathrm{WO}_{3}+2 \mathrm{Li} \rightarrow \mathrm{W}_{\mathrm{W}}^{\prime \prime}+2 \mathrm{Li}_{\mathrm{i}}+3 \mathrm{O}_{\mathrm{O}}^{x}
$$

Lee et $a .^{31-33}$ proposed that (transparent) pristine amorphous tungsten trioxide thin films mainly contain $\mathrm{W}^{6+}$ and $\mathrm{W}^{4+}$ and that coloration is due to the formation of $\mathrm{W}^{5+}$ performing the following transition ${ }^{33}$

$$
h \nu+\mathrm{W}^{4+}(\mathrm{A})+\mathrm{W}^{5+}(\mathrm{B}) \rightarrow \mathrm{W}^{5+}(\mathrm{A})+\mathrm{W}^{4+}(\mathrm{B})
$$

and the transition from $\mathrm{W}^{5+}$ to $\mathrm{W}^{6+}$ described by eqn (2).

In contrast to the findings of Lee et al., our results clearly show that our pristine nanocrystalline $\mathrm{WO}_{3}$ is almost stoichiometric as only $\mathrm{W}^{6+}$ is found, and a notable coloration is only possible due to the existence of $\mathrm{W}^{4+}$, most likely performing the following bipolaronic transition

$$
h \nu+\mathrm{W}^{4+}(\mathrm{A})+\mathrm{W}^{6+}(\mathrm{B}) \rightarrow \mathrm{W}^{6+}(\mathrm{A})+\mathrm{W}^{4+}(\mathrm{B}),
$$

which is much more likely than single polaronic transitions (eqn (2) and (7)) due to the large amount of $\mathrm{W}^{6+}$.

In contrast to this interpretation, Zhong et al. concluded from their XRD experiments that the potential plateaus in galvanostatic insertion experiments correspond to phase transitions of the crystal structure from monoclinic to tetragonal and from tetragonal to cubic. ${ }^{20}$ As shown in the next section, our ex situ XRD analyses indeed show increasing symmetry of the films as lithium is inserted, however, a distinct phase 
transition at the galvanostatic potential plateaus/CV peaks is only found for the second plateau at $2.45 \mathrm{~V}$.

\subsection{X-ray diffraction}

In order to classify the quality of our synthesis procedure, preliminary XRD measurements on two powder samples were carried out. These powders were prepared by heating the sol-gel precursor to $300{ }^{\circ} \mathrm{C}$ and $450{ }^{\circ} \mathrm{C}$ for $8 \mathrm{~h}$. Interestingly, unlike other groups, ${ }^{21}$ we already found a nanocrystalline phase with an average crystallite size of $7 \mathrm{~nm}$ in the sample heated at $300{ }^{\circ} \mathrm{C}$, which is an unusually low temperature for the preparation of crystalline samples from sol-gel precursors. The observed broad reflections could be attributed to the orthorhombic high-temperature phase of $\mathrm{WO}_{3}$ (usual range: $467{ }^{\circ} \mathrm{C}$ to $680{ }^{\circ} \mathrm{C}$, space group Pnma), ${ }^{34}$ and Rietveld refinement (see ESI, $\dagger$ S1) shows excellent agreement of the measured data with the theoretical structural model. Hence, the chimie douce approach does indeed promote formation of the kinetically stable instead of the thermodynamically stable product, which is a well-described phenomenon. ${ }^{35}$ The sample heated at $450{ }^{\circ} \mathrm{C}$ revealed typical reflections of monoclinic $\mathrm{WO}_{3}$ (space group $P 2_{1} / n$ ) with an average crystallite size of $23 \mathrm{~nm}$. The results of the Rietveld refinement can be found in the ESI, $\dagger \mathrm{S} 2$. These results clearly document the identity of our $\mathrm{WO}_{3}$ samples.

Structural changes and the evolution of crystallinity in the films during insertion of lithium will be discussed in the following. Fig. 6 shows the diffraction diagrams of the three thin film samples on FTO-coated $\mathrm{SiO}_{2}$, corresponding to the charge states of the pristine $\mathrm{WO}_{3}$ film and intercalated films up to plateau I and II, respectively. Reflections that can be attributed to the FTO substrate are marked by vertical gray dashed lines. Considering the shape and size of the strongest reflections at $2 \theta \approx 24^{\circ}$, a salient effect of the preferential orientation in the samples can be determined. Away from these reflections, broad and minor features are found, revealing the nanocrystalline nature of the samples. In contrast to the common literature, reporting similar methods for the preparation of $\mathrm{WO}_{3}$ thin films, ${ }^{19,21}$ our pristine sample does not reveal the expected monoclinic structure. Instead, indexation of the few mostly very poor reflections in the diffraction diagram points to tetragonal symmetry.

Furthermore, a direct comparison of the diffraction diagrams of the pristine sample and the sample at the first plateau at $2.73 \mathrm{~V}$ gives strong evidence for the similarity of the two corresponding crystal structures. According to the literature ${ }^{20}$ the $\mathrm{Li}_{x} \mathrm{WO}_{3}$ sample at the first plateau reveals a tetragonal crystal lattice, which matches our findings. Profile refinements for both samples, leaving out the reflections of the FTO substrate, led to decent results. Hence, both samples show tetragonal symmetry and the first insertion step obviously proceeds without a phase transformation. However, we cannot fully exclude that the first plateau-like potential curve is due to the coexistence of a tetragonal $\mathrm{WO}_{3}$ and a tetragonal $\mathrm{Li}_{x} \mathrm{WO}_{3}$ phase. It may be concluded that this lack of structural alteration entails minor insertion of lithium ions/electric charge only, and therefore a poor transmission change results in the vicinity of the first peak. Looking at the diffraction diagram of the

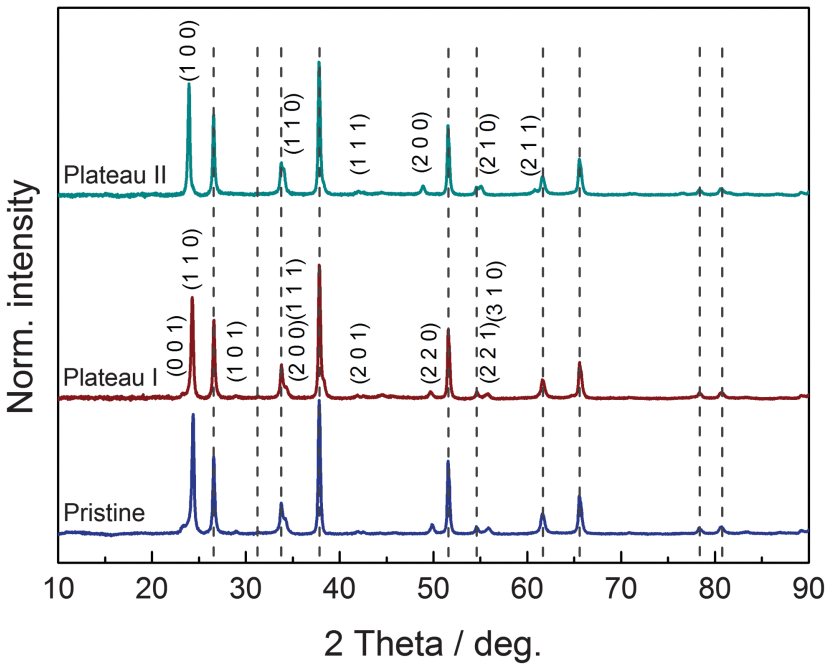

Fig. 6 Diffraction diagrams of the pristine $\mathrm{WO}_{3}$ film (bottom trace) and the lithium-inserted films formed by galvanostatic discharge down to plateau I at $2.73 \mathrm{~V}$ (center trace) and plateau II at $2.45 \mathrm{~V}$ (top trace). FTO substrate reflections are marked by gray dashed lines. Indices for reflections attributable to the tetragonal (pristine, plateau I) and cubic phases (plateau II) are depicted.

$\mathrm{Li}_{x} \mathrm{WO}_{3}$ sample at the second plateau at $2.45 \mathrm{~V}$, a structural change becomes visible. In agreement with the literature, a phase transformation to the cubic structure of $\mathrm{Li}_{x} \mathrm{WO}_{3}$ is observed. Certain reflections of the tetragonal system disappear due to extinction rules, as can be seen from the indices of the tetragonal and cubic lattice in Fig. 6. In this particular case, one could deduce that the phase transformation promotes the insertion of charge carriers and leads to a higher state of coloration for the second peak. The unit cell volume of the samples increases with increasing lithium content/further discharge level, as expected. While the pristine film has a unit cell volume of $51.20(2) \times 10^{6} \mathrm{pm}^{3}$ per formula unit, the unit cell volume of the sample at the first plateau is $52.65(3) \times 10^{6} \mathrm{pm}^{3}$ per formula unit. For the sample at the second plateau, a unit cell volume of $52.94(1) \times 10^{6} \mathrm{pm}^{3}$ is found.

The average crystallite size in the thin films was calculated via Williamson-Hall analysis, using $\mathrm{LaB}_{6}$ powder (NIST Standard Reference Material 660B) as an external standard for instrumental line broadening and omitting the FTO substrate reflections. Using this method, an increase in the average crystallite size from $11 \mathrm{~nm}$ for the pristine $\mathrm{WO}_{3}$ film to $20 \mathrm{~nm}$ for the sample at the first plateau and $22 \mathrm{~nm}$ for the sample at the second plateau is observed. Apparently, besides inducing structural changes, insertion of lithium leads to crystallite growth. In order to check on the reversibility of this behavior, a sample that was oxidized to the deintercalated (tetragonal) state at $4 \mathrm{~V} v s$. $\mathrm{Li} / \mathrm{Li}^{+}$after 10 cycles was analyzed. For this sample, an average crystallite size of $26 \mathrm{~nm}$ is found, which is even bigger than the value identified for the cubic sample during the first cycle. Hence, the nanocrystalline samples do not fully recover and with growing crystallite size, extraction of $\mathrm{Li}$ becomes slow due to the reduced surface area. This observation is in line with effects described by 
Limaye et al. ${ }^{19}$ who state that the number of ions trapped inside the chains between $\mathrm{WO}_{6}$ octahedra increases with the cycle number, resulting in structural disorder and degradation of the electrochromic properties of $\mathrm{WO}_{3}$. This interpretation could provide an explanation for the decrease in differential transmission change we observed for the first reduction peak during lithium insertion after several cycles.

However, one should keep in mind that the data presented here should be regarded with caution, as values for crystallinity and unit cell volume are, in general, difficult to obtain for thin film samples.

\section{Conclusions}

We successfully synthesized nanocrystalline tungsten trioxide thin films via a sol-gel based dip coating process. Electrochemical insertion of hydrogen or lithium results in a transmission change, which yields a blue color to the film. In CV experiments two distinct redox reaction peaks are observed, which correspond to a two-step reduction of the material. We observe this two-step insertion process for both hydrogen and lithium. By combining optical spectroscopy with electrochemical experiments in situ we were able to show that the first reduction step at high electrode potential is characterized by both a lower amount of the inserted electric charge and more importantly a much lower decrease in optical transmission compared to the second step. Hence coloration of nanocrystalline $\mathrm{WO}_{3}$ at low potential is more efficient than at higher potentials. Using XPS we showed that these two reduction steps denote the reduction from initial $\mathrm{W}^{6+}$ to $\mathrm{W}^{5+}$ at $-0.05 \mathrm{~V} v s$. $\mathrm{Ag} / \mathrm{AgCl}$ and $2.73 \mathrm{~V} v s$. $\mathrm{Li} / \mathrm{Li}^{+}$and from $\mathrm{W}^{5+}$ to $\mathrm{W}^{4+}$ at $-0.3 \mathrm{~V}$ vs. $\mathrm{Ag} / \mathrm{AgCl}$ and $2.45 \mathrm{~V} v s$. $\mathrm{Li} / \mathrm{Li}^{+}$. UV-Vis spectroscopy showed that there is no noticeable transmission change from $\mathrm{W}^{6+}$ to $\mathrm{W}^{5+}$, whereas the transmission decreases strongly for $\mathrm{W}^{4+}$. In essence, we conclude that electrochromism in nanocrystalline $\mathrm{WO}_{3}$ is mainly caused by the formation of $\mathrm{W}^{4+}$. That is, nanocrystalline $\mathrm{WO}_{3}$ shows only a significant transmission change when it is reduced to a $\mathrm{W}^{4+}$ state. A possible transition could be $\mathrm{W}^{4+} \rightarrow \mathrm{W}^{5+}$, but due to the large amount of $\mathrm{W}^{6+}(50 \%)$ a bipolaronic transition, $\mathrm{W}^{4+} \rightarrow \mathrm{W}^{6+}$, is more likely. XRD measurements showed that the electrochemical reduction is accompanied by structural alteration of the film towards higher symmetry. However, a two-step mechanism is not observed here. Only one structural transition, i.e. the transition from initial tetragonal to cubic $\mathrm{WO}_{3}$, is found when $\mathrm{W}^{4+}$ is formed. XRD measurements also prove that the nanocrystalline $\mathrm{WO}_{3}$ experiences grain growth by conventional Ostwald ripening.

\section{Acknowledgements}

We thank B. M. Smarsly, J. Sann, D. Krüger and C. Schneider for experimental support and fruitful discussions. This work was funded by the Hessen State Ministry of Higher Education, Research and the Arts (LOEWE initiative, STORE-E).

\section{Notes and references}

1 G. Niklasson and C. Granqvist, J. Mater. Chem., 2007, 17, 127-156.

2 K. Bange, Sol. Energy Mater. Sol. Cells, 1999, 58, 1-131.

3 C. G. Granqvist, Sol. Energy Mater. Sol. Cells, 2012, 99, 1-13.

4 P. M. S. Monk, Crit. Rev. Solid State Mater. Sci., 1999, 24, 193-226.

5 C. G. Granqvist, Sol. Energy Mater. Sol. Cells, 2000, 60, 201-262.

6 S. K. Deb, Appl. Opt., 1969, 3, 192.

7 C. M. Lampert, Sol. Energy Mater., 1984, 11, 1-27.

8 J. S. E. M Svensson and C. G. Granqvist, Sol. Energy Mater., 1984, 11, 29-34.

9 T. Tesfamichael, M. Arita, T. Bostrom and J. Bell, Thin Solid Films, 2010, 518, 4791-4797.

10 D. T. Gillaspie, R. C. Tenent and A. C. Dillon, J. Mater. Chem., 2010, 20, 9585-9592.

11 D. R. Rosseinsky and R. J. Mortimer, Adv. Mater., 2001, 13, 783-793.

12 B. W. Faughnan and R. S. Crandall, Top. Appl. Phys., 1980, 40, 181-211.

13 S.-H. Lee, M. J. Seong, H. M. Cheong, E. Ozkan, E. C. Tracy and S. K. Deb, Solid State Ionics, 2003, 156, 447-452.

14 O. F. Schirmer and E. Salje, Solid State Commun., 1980, 33, 333-336.

15 J.-G. Zhang, D. K. Benson, C. E. Tracy, S. K. Deb and A. W. Czanderna, J. Electrochem. Soc., 1997, 144, 2022-2026.

16 S. K. Deb, Sol. Energy Mater. Sol. Cells, 2008, 92, 245-258.

17 E. Broclawik, A. Góra, P. Liguzinski, P. Petelenz and H. A. Witekb, J. Chem. Phys., 2006, 124, 054709.

18 B. W. Faughnan, R. S. Crandall and M. A. Lampert, Appl. Phys. Lett., 1975, 27, 275.

19 M. V. Limaye, J. S. Chen, S. B. Singh, Y. C. Shao, Y. F. Wang, C. W. Pao, H. M. Tsai, J. F. Lee, H. J. Lin, J. W. Chiou, M. C. Yang, W. T. Wu, J. S. Chen, J. J. Wu, M. H. Tsai and W. F. Pong, RSC Adv., 2014, 4, 5036-5045.

20 Q. Zhong, J. R. Dahn and K. Colbow, Phys. Rev. B: Condens. Matter Mater. Phys., 1992, 46, 4.

21 T. Brezesinski, D. Fattakhova Rohlfing, S. Sallard, M. Antonietti and B. A. Smarsly, Small, 2006, 2, 1203-1211. 22 J. Wallys, J. Teubert, F. Furtmayr, D. M. Hofmann and M. Eickhoff, Nano Lett., 2012, 12, 6180.

23 H. Kamal, A. A. Akl and K. Abdel-Hady, Physica B, 2004, 349, 192-205.

24 A. Georg, A. Georg, U. O. Krasovec and V. Wittwer, J. New Mater. Electrochem. Syst., 2005, 8, 317-325.

25 J. I. Jeong, J. H. Hong, J. H. Moon and J.-S. Kang, J. Appl. Phys., 1996, 79, 1996.

26 M. Stolze, B. Camina, F. Galbertb, U. Reinholzc and L. K. Thomas, Thin Solid Films, 2002, 409, 254-264.

27 L. Su and Z. Lu, J. Phys. Chem. Solids, 1998, 59, 1175-1180. 28 A. Henningsson, A. Stashans, A. Sandell, H. Rensmo, S. Södergren, H. Lindström, L. Vayssieres, A. Hagfeldt, S. Lunell and H. Siegbahn, Adv. Quantum Chem., 2004, 47, 23-36.

29 A. Siokou, S. Ntais, S. Papaefthimiou, G. Leftheriotis and P. Yianoulis, Surf. Sci., 2004, 566-568(part 2), 1168-1173. 
30 A. Romanyuk and P. Oelhafen, Sol. Energy Mater. Sol. Cells, 2006, 90, 1945-1950.

31 S.-H. Lee, H. M. Cheong, J.-G. Zhang, C. E. Tracy, A. Mascarenhas, D. K. Benson and S. K. Deb, Electrochim. Acta, 1999, 44, 3111.

32 S.-H. Lee, H. M. Cheong, J.-G. Zhang, A. Mascarenhas, D. K. Benson and S. K. Deb, J. Appl. Phys., 1999, 74, 242.
33 S.-H. Lee, H. M. Cheong, C. E. Tracy, A. Mascarenhas, A. W. Czanderna and S. K. Deb, J. Appl. Phys., 1999, 75, 1541.

34 E. Salje, Acta Crystallogr., Sect. B: Struct. Crystallogr. Cryst. Chem., 1977, 33, 574-577.

35 R. J. Cohen and G. B. Benedek, J. Phys. Chem., 1982, 86, 3696-3714 